\title{
THE STUDY OF ADSORPTION CAPACITY ON BONE CHAR IN WASTEWATER TREATMENT CONTAINED ARSENIC ION
}

\author{
VO THANH CONG, DO QUY DIEM, AND NGUYEN VAN SON \\ Industrial University of Ho Chi Minh City, \\ vothanhcong@iuh.edu.vn
}

\begin{abstract}
Wastewater treatment is one of the urgent and important issues in environmental protection. Nowadays, many methods to treat wastewater in industry were found to which adsorption applied as an effective method. Among possible adsorbents, bone char appeared to be of important application especially for heavy metals. In this study, we are applied char bone char sample as an adsorbent at optimal condition on previous investigation to adsorb arsenic ion (type of $\mathrm{As}^{5+}$ ion) contained in wastewater. The detail in experimental performance, the initial concentration, capacity adsorption, and adsorption time at optimal condition of arsenic ion solution were examined. The results of arsenic adsorption process were found that the optimization of initial concentration to be As5 sample with adsorption capacity of $0.124 \mathrm{mg}$ arsenic ion/g bone char at time of 60 minute. In addition, the optimal adsorption time on As5 sample was also determined as 90 minutes with capacity adsorption of $0.02 \mathrm{mg}$ arsenic ion/ $\mathrm{g}$ bone char. The positive research results of the adsorption on bone char have pointed out a possible application of bone char as an adsorbent in future.
\end{abstract}

Keyword. Bone char; arsenic ion; adsorption capacity; wastewater; adsorbent.

\section{INTRODUCTION}

Bone char has been known since 2650 years, which used to be a paint substance in the inner walls of ancient tombs in Egypt, and in this dynasty [1,2]. However, by the 1990s a new idea of trade occurred. Bone char was invented to use sugar filtration during sugar crystallization, the invention was recognized in 1812. A few years ago, a team of researchers found that bone char was better used during the reduction process color in pomegranate or in vinegar. Historically, bone char was often used in sugar refining as a decolorizing and deashing agent, particularly in cane sugar as this contains more colored impurities. Bone char possesses a low de-coloration capacity and must be used in large quantities[3]. However, it has been also able to remove various inorganic impurities; most importantly sulfates and the ions of magnesium and calcium. The removal of these was beneficial, as it reduces the level of scaling later in the refining process, when the sugar solution was concentrated [4]. Modern alternatives to bone char include activated carbon and ion-exchange resins.

Bone char carbon was a unique carbonaceous adsorbent manufactured from the treatment and carbonization of selected grades of animal bone and was used for liquid phase filtration to remove inorganic and organic species such as colored compounds [5] and many heavy metals [6-10]. Bone char was different from activated carbon in that it contains both carbon surface area and hydroxyapatite lattice surface area.

The tricalcium phosphate in bone char can be used to remove fluoride [11-13] and metal ions from water, making it useful for the treatment of drinking supplies. Bone char has been also the oldest known water de-fluoridation agent and was widely used in the United States from the 1940s through to the 1960s [14]. As it can be generated cheaply and locally it was still used in certain developing countries, such as Tanzania [15]. Bone chars usually have lower surface areas than activated carbons, but present high adsorptive capacities for certain metals, particularly those from group 12 (copper, zinc, and cadmium) [16]. Other highly toxic metal ions, such as those of arsenic [17] and lead [18] may also be removed. The practical example of the use of bone char in water purification has been demonstrated in Nano-filter invention in Tanzania [19]. 


\section{WASTEWATER TREATMENT CONTAINED ARSENIC ION}

The pollution of water bodies with toxic substances, such as heavy metals, is ubiquitous in developing countries like Viet Nam due to increased industrial activities. The importance of removing dissolved heavy metals from water was a primary concern for society because heavy metals represent a risk to both public and environmental health. These pollutants are toxic and carcinogenic, and they can easily enter the food chain [21, 21]. According to the EPA, heavy metals are considered priority pollutants and must be eliminated or reduced from any water body that may or may not come into contact with the environment $[22,23]$.

Arsenic and its compounds, especially the trioxide, were used in the production of pesticides, treated wood products, herbicides, and insecticides. These applications are declining due to the toxicity of arsenic and its compounds [24]. Arsenic contamination of groundwater is a problem that affects millions of people across the world. The United States' Environmental Protection Agency states that all forms of arsenic are a serious risk to human health [25]. The United States' Agency for Toxic Substances and Disease Registry ranked arsenic as number 1 in its 2001 Priority List of Hazardous Substances at Superfund sites[26]. Arsenic was classified as a Group-A carcinogen [25].

Inorganic arsenic and its compounds, upon entering the food chain, have been progressively metabolized through a process of methylation [26,27]. For example, the mold Scopulariopsis brevicaulis produces significant amounts of trimethylarsine if inorganic arsenic is present [28]. The organic compound arsenobetaine was found in some marine foods such as fish and algae, and also in mushrooms in larger concentrations. The average person's intake is about $10-50 \mu \mathrm{g} / \mathrm{day}$. Values about $1000 \mu \mathrm{g}$ are not unusual following consumption of fish or mushrooms, but there has been little danger in eating fish because this arsenic compound is nearly non-toxic [29]. The Occupational Safety and Health Administration has set the permissible exposure limit (PEL) to a time-weighted average (TWA) of 0.01 $\mathrm{mg} / \mathrm{m} 3(0.01 \mathrm{ppb})$, and the National Institute for Occupational Safety and Health (NIOSH) has set the recommended exposure limit (REL) to a 15-minute constant exposure of $0.002 \mathrm{mg} / \mathrm{m} 3(0.002 \mathrm{ppb})$ [30]. The PEL for organic arsenic compounds has been a TWA of $0.5 \mathrm{mg} / \mathrm{m}^{3}[31](0.5 \mathrm{ppb})$.

Adsorption occurs when insoluble two-phase contact is the solid phase (adsorbent) with the gas or liquid phase (adsorbates). In it, the adsorbed substance will go from the liquid phase (or gas) to the solid phase until the concentration of the dispersion content between the two phases was balanced. In principle, the techniques used to perform the contact between two insoluble phases are possible for adsorption. Another liquid-solid process is ion exchange, which is a reversible exchange between a certain solid and electrolyte solution. The process involves the chemical nature of the interaction between ions and solids and the diffusion of ions in the solid phase. This was a more complex phenomenon but adsorption techniques are similar. Adsorption can be carried out for many activities that are difficult to achieve by other common techniques such as absorption, distillation, ion exchange membranes. Recently, applications for adsorption process have been developed rapidly because of the increasing demand for quality of environmental protection, and the advantages for adsorption process meet the above requirements. New adsorbents are synthesized continuously to improve adsorption properties better. However, to study a new adsorbent for a new reaction that takes several months to several years, so the scientists understand more about the adsorption mechanism that helps them design and simulate too, the adsorber was accurate and faster. The most well-known adsorption application was the cleaning of wastewater, especially urban wastewater, but has is also used for cleaning gas, used as a means to separate substances from liquid mixtures. There are many applications for adsorption, but the choice to find adsorbents has been better for finding an adsorption process [32,33]. To deal with metalcontaminated water, different methods have been suggested to remove metals from aqueous solution including chemical precipitation, ion exchange, electrochemical treatment, and membrane technologies [32]. Among the methods, biosorption technique is the most common and cost-effective. This was because biosorbents are environmentally friendly and readily available in large quantities, and one of the most popular biosorbents was bone char.

From the current situation of the agricultural and livestock waste sources that need to be addressed, as well as the important applications of bone char, it can be seen that construction of bone char product synthesis process from Different sources of waste, and their application in the fields of publicagriculture are significant while handling environmental pollutants, while creating products with high 


\section{WASTEWATER TREATMENT CONTAINED ARSENIC ION}

application value, this is a scientific problem. It has urgent and necessary to be deployed. However, the current research has not been implemented completely and widely into industrial scale. Studies need to be developed, experimented, as well as knowledge to run on a small scale first needs to be done. To do this, the first is to build the process of synthesizing bone char and application in environmental treatment with the scale of applied research in the laboratory, this is the main goal in the project. which we did.

\section{MATERIAL AND METHODS}

\subsection{Raw materials}

Currently in Viet Nam there are many the cooking shop of noodle soup with beef to provide food for humans. In the process of noodle soup cooking with beef, cow bones are mixed together with noodle soup. The Final of soup cooking process, cow bones are a waste raw (called as waste cow bone) which collected as raw materials to produce bone char in this study. The samples of raw materials for the experiment in this work is readily available and easy to find. From the collected sample of waste cow bone to produced bone char product is illustrated in Figure 1.

(a)

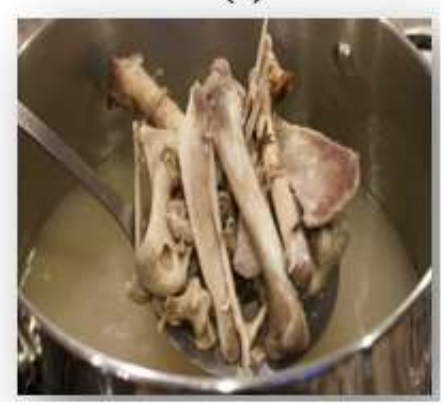

(b)

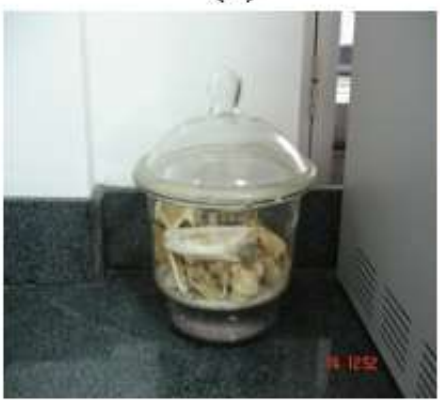

(c)

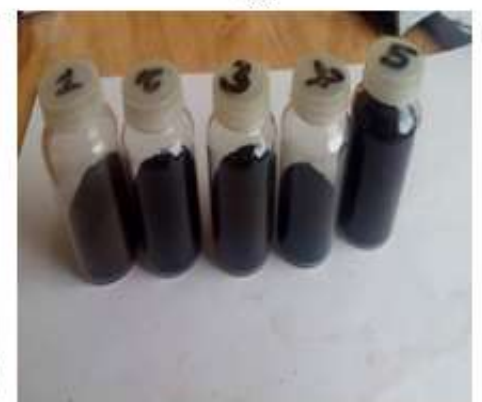

Figure 1. Bone image making a model of pre-processing research. It noted that the Figure from (a) to (c) were the raw of cow bone waste, cow bone after drying, and cow bone after calcinating, respectively

The waste cow bone collected from the noodle cooking shops in general has completely cleaned the marrow, leaving only the remaining fat adhering to the bone. Conduct this fat treatment to obtain a sample of bone raw material. The resulted process from the raw material of waste cow bone to bone char product is shown in scheme 1. 


\section{WASTEWATER TREATMENT CONTAINED ARSENIC ION}

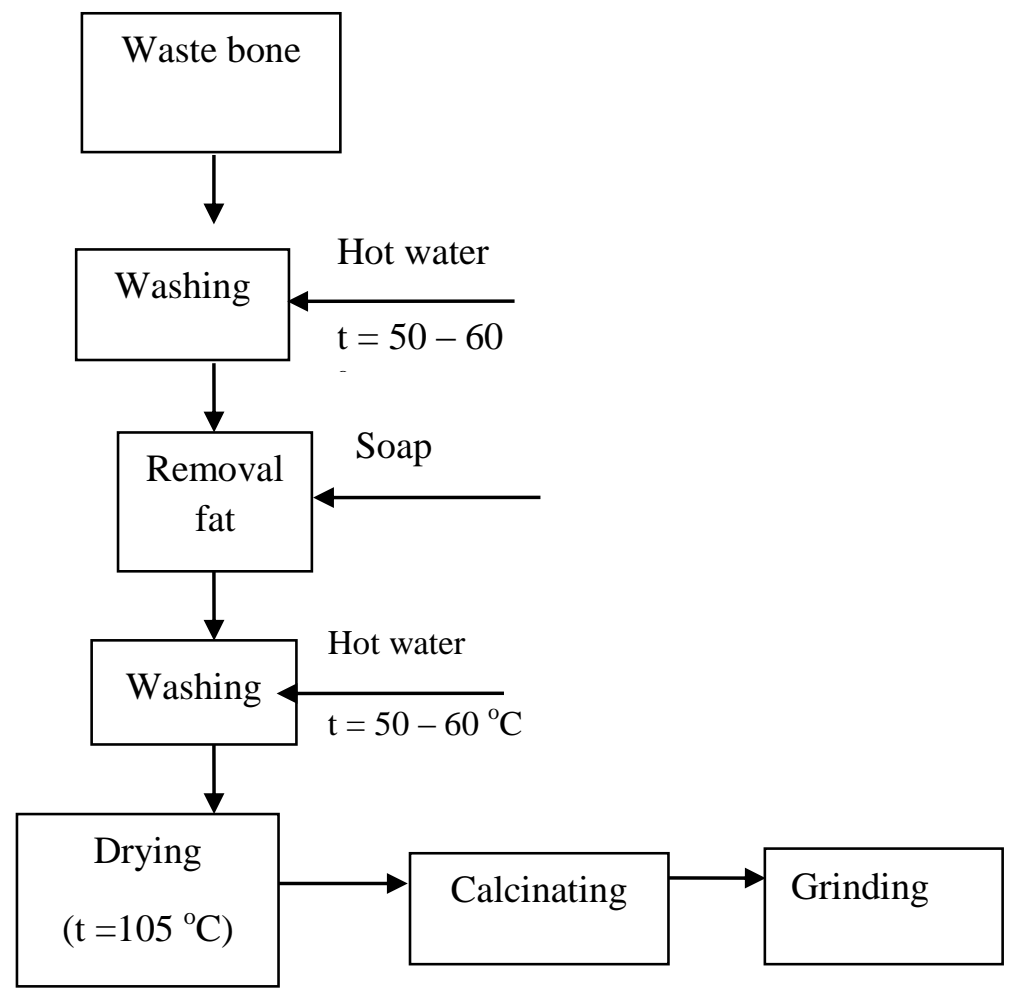

Scheme 1. Process of processing bone material

\subsection{Method}

To produce bone char, the waste bones need to be heated in a reducing medium (heated in a closed tank without oxygen). Waste cow bone samples after soups cooking process were taken to weigh and determine the initial bone mass. After weighing, we proceed to dry at $105{ }^{\circ} \mathrm{C}$, about 2 hours and burned at different temperatures. The calcination of watse cow bone to bone char product and measured characteristic surface of bone char product at optimal condition in syntheris process have been performed in previous our study [34]. In this works, we have only carried out a surveying condition of bone calcination at the time burning of 120 minute, corresponding to the temperature burning of $650^{\circ} \mathrm{C}$. By doing this, the product sample of bone char with experimental symbol as BB $650-120$ sample were used to study continously the adsorption capacity of contained arsenic ion solution. The results of bone char sample, namely BB $650-120$ before and after grinding at the average particle size of $1 \mathrm{~mm}$ which used for this study is represented in Figure 2.
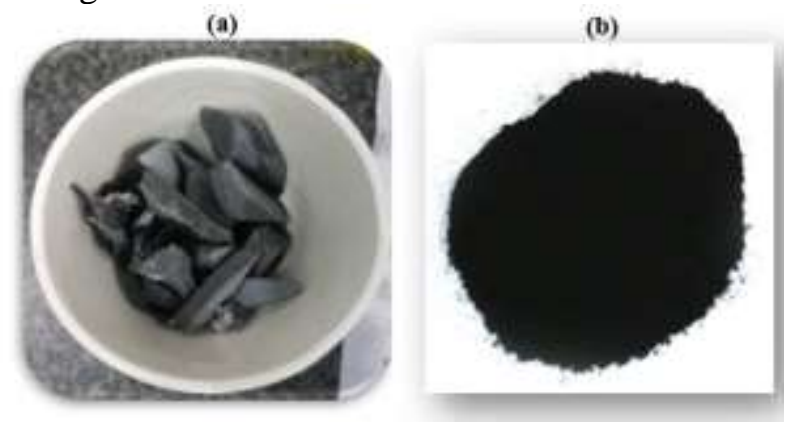

Figure 2. The sample of bone char product with BB 650-120 symbol. In which, Figure 2(a) and 2(b) were the bone char sample before and after grinding

In experiments, the sample of wastewater solution contained arsen in the type of $\mathrm{AsO}_{4}{ }^{3-}\left(\mathrm{As}^{+5}\right)$ ion at concentration of $1000 \mathrm{ppm}$ were diluted to each sample at different concentration such as $10 \mathrm{ppm}, 5 \mathrm{ppm}$, 
WASTEWATER TREATMENT CONTAINED ARSENIC ION

$2.5 \mathrm{ppm}, 1 \mathrm{ppm}, 0.5 \mathrm{ppm}$, and denoted corresponding to the symbol of As10, As5, As2.5, As1, As0.5, respectively. All diluted solutions of arsenic ion chosen as initial samples (adsorbates) were then used to try capacity adsorption with adsorbent as bone char product.

It noted that the capacity adsorption of arsenic solution on bone char, the concentrated arsenic ion after adsorption was measured by AAS (atomic adsorption spectrophotometer) method. The adsorption capacity $\left(\mathrm{C}_{\mathrm{ads}}\right.$ in $\mathrm{mg} / \mathrm{g}$ of unit) of arsenic ion were calculated as (1) follows:

$$
\mathrm{C}_{\mathrm{ads}}=\frac{\left(\mathrm{C}_{0 \mathrm{i}}-\mathrm{C}_{\mathrm{ei}}\right) \times \mathrm{V}}{1000 \times \mathrm{m}}
$$

Where, $\mathrm{C}_{0 \mathrm{i}}(\mathrm{ppm})$ and $\mathrm{C}_{\mathrm{ei}}(\mathrm{ppm})$ are initial and equilibrium concentrations (at concentration after adsorption) of arsenic ion solution in each sample, respectively. $\mathrm{V}$ is the volume of adsorption solution $(\mathrm{L})$, and $\mathrm{m}(\mathrm{g})$ as the weight of biochar.

\section{RESULTS AND DISCUSSION}

\subsection{Surveying the effective adsorption concentration of arsenic ion on bone char}

In experimental performance, taking $30(\mathrm{ml})$ volume of each one waste water sample was mixed with $1 \mathrm{~g}$ ) weight of bone char, and put it onto a shaker to rotate with the speed of 250 revolutions per minute (rpm) at the time of 60 minutes. After 60 minutes, the sample was filtered to separate the treatment solution and bone char. The treatment solution sample was then analyzed to determine the arsenic ion concentrations after adsorption. By doing this, capacity adsorption of arsenic ion solution on bone char adsorbents were determined and listed in table 1.

Table 1. The effects of arsenic ion concentration on bone char adsorbents

\begin{tabular}{ccc}
\hline $\mathrm{C}_{\mathrm{oi}}$ & $\mathrm{C}_{\mathrm{ei}}$ & $\mathrm{C}_{\mathrm{ads}}$ \\
\hline 10 & 1,080 & 0,268 \\
5 & 0,880 & 0,124 \\
2,5 & 0,730 & 0,053 \\
1 & 0,004 & 0,030 \\
0,5 & 0,002 & 0,015 \\
\hline
\end{tabular}

It is an observation from table 3 shown that after arsenic ion concentration decreased rapidly in each experimental samples at time constant. This means that bone char is a good adsorbent to adsorb arsenic ion in aqueous solution.

To study the effects of arsenic ion concentration relate to adsorption capacity, we have resulted the relation between concentration and capacity adsorptions to obtain the curved line of adsorption isotherm, shown in Figure 3.

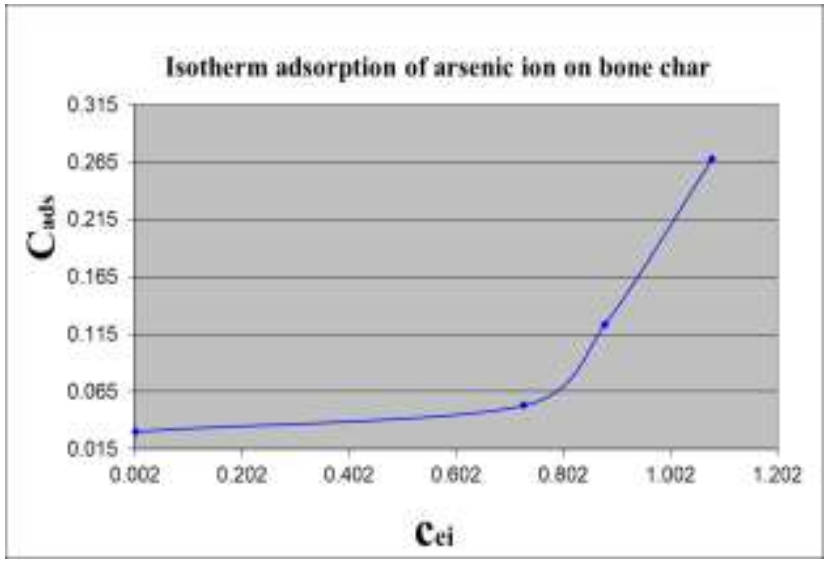

Figure 3. The curved line of arsenic isotherm adsorption 


\section{WASTEWATER TREATMENT CONTAINED ARSENIC ION}

The results of isothermal adsorption from Figure 3 are observed that, in $\mathrm{C}_{\mathrm{ei}}$ range from $0.002 \mathrm{ppm}$ to $0.730 \mathrm{ppm}$, the $\mathrm{C}_{\mathrm{ads}}$ of arsenic ion on bone char increased with the linear. Furthermore, $\mathrm{C}_{\mathrm{ei}}$ from 0.730 to $0.880 \mathrm{ppm}, \mathrm{C}_{\mathrm{ads}}$ is creased slowly, and to $1.080 \mathrm{ppm}, \mathrm{C}_{\mathrm{ads}}$ got back the increase with linear. These are showing that the adsorption isotherm of arsenic ion on bone char in this works can be occured with multilayer adsorption. In which, the mono-layer adsorption following langmuir-Hinshellwood is endded at $\mathrm{C}_{\mathrm{e}}$ of $0.880 \mathrm{ppm}$ of As5 sample, correspoding to minimum $\mathrm{C}_{\mathrm{ads}}$ of $0.124 \mathrm{mg}$ arsenic ion/ $\mathrm{g}$ bonechar. This is to say that initial concentration of arsenic is the best at 5ppm used to adsorb on VNBC product.

\subsection{Surveying the effective adsorption time of arsenic ion on bone char}

Because the initial concentration of As5 sample at $5 \mathrm{ppm}$ is used to give a best adsorption. Therefore, in this experiment, we have chosen the initial concentration of arsenic solution sample from minimum of $1 \mathrm{ppm}$ to maximum of $5 \mathrm{ppm}$ to perform continuously in experimental surveying of adsorption time. By doing experimental similarity, the solution of arsenic-containing wastewater is diluted to perform two sample with initial concentration as $5 \mathrm{ppm}$ (As5) and $1 \mathrm{ppm}$ (As1), with the volume of each sample as $20 \mathrm{~mL}$. Using $5 \mathrm{~g}$ of bone char was added in each sample, and put it on the shaker at a speed of $250 \mathrm{rpm}$. The change of surveying time $\left(\mathrm{t}_{\text {survey }}\right)$ from 30 to 180 minutes. At each surveying time, the adsorbed sample was filtered to separate the treatment solution and bone char after adsorption. Treatment solution was then measured by AAS analysis to determine the adsorption concentration $\left(\mathrm{C}_{\mathrm{e} i}\right)$. The results of adsorption arsenic concentrations were listed in table 2 .

Table 2. Relations in arsenic concentrations adsorbed to time on bone char

\begin{tabular}{cccc}
\hline $\mathrm{t}_{\text {survey }}$ & $\mathrm{C}_{\mathrm{ei}}$ & & $\mathrm{C}_{\mathrm{ei}}$ \\
\cline { 2 - 3 } & $\mathrm{As} 1$ & $\mathrm{As} 5$ \\
\hline 30 & 0,067 & & 1,258 \\
60 & 0,066 & 0,670 \\
90 & 0,064 & 0,490 \\
180 & 0,064 & 0,302 \\
\hline
\end{tabular}

Based on the results of changed adsorption concentration, a relation between surveying time and arsenic $\mathrm{C}_{\mathrm{ei}}$ of adsorption was presented in Figure 4.

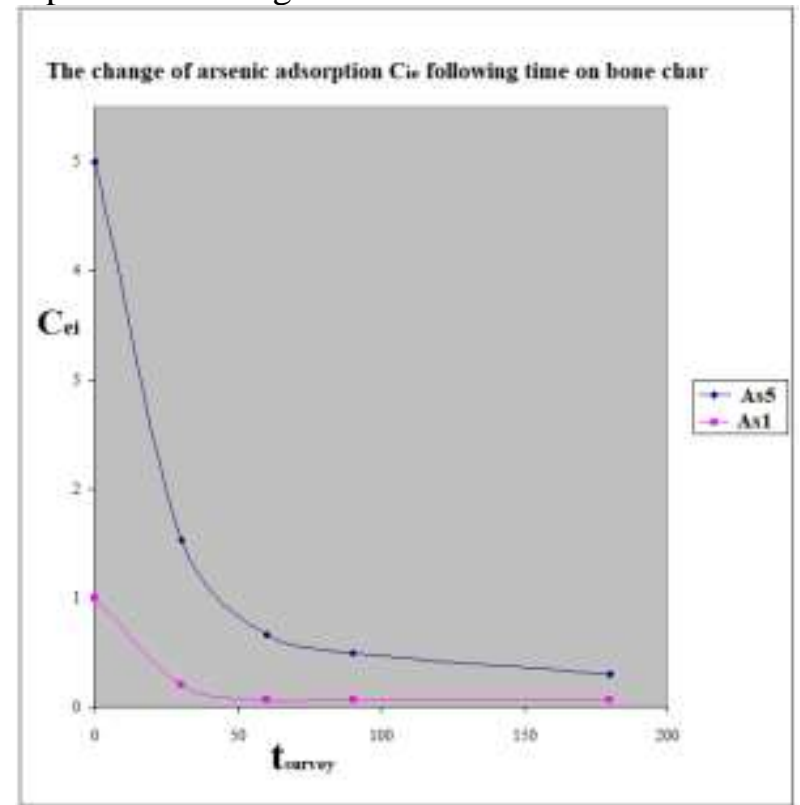

Figure 4. The effects of arsenic adsorption time to concentration on bone char

It is observed in Figure 4 that the $\mathrm{C}_{\mathrm{ei}}$ of arsenic ion solution on bone char decreased rapidly in time change from 30 to 90 minutes for both As1 and As5, this meaned that arsenic solution is most strongly absorbed by bone char. Within 90 minutes or more, the concentration of arsenic adsorbed decreased 


\section{WASTEWATER TREATMENT CONTAINED ARSENIC ION}

slowly, indicating that there is occuring an adsorption balance between arsenic ion solution and bone char adsorbent. Specially, at the time of 90 minute, the maximum concentration of As1 and As5 samples are $0.064 \mathrm{ppm}$ and $0.490 \mathrm{ppm}$, respectively. Hereafter, it follow us to conclude that adsorption balance of arsenic ion on bone char is at 90 minutes, corresponding to the highest adsorption capacity as $0.004 \mathrm{mg}$ arsenic ion/g bone char for As1 sample and $0.02 \mathrm{mg}$ arsenic ion/g bone char for As5 sample.

\section{CONCLUSION}

From resulted experiments in this study, we draw the following conclusions such as,

1) Based on bovine bones as waste of food processing, we have identified the appropriate technology regime for producing bone char at the temperature of $650{ }^{\circ} \mathrm{C}$ for 120 minutes. After calcinating, bone char was crushed to a particle size about $1 \mathrm{~mm}$ to apply as an adsorbent.

2) The relations between the initial concentration and time adsorption of $\mathrm{AsO}_{4}{ }^{3-}$ solution to adsorption capacity on bone char were considered to which initial concentration of As5 sample found with the adsorption capacity of $0.124 \mathrm{mg}$ arsenic ion/ $\mathrm{g}$ bonechar at time of 60 minute. In addition, the isotherm adsorption was found to understand the principle of adsorption processing in wastewater treatment technology contained asenic ion.

3) The conditional adsorption optimum of As1 and As5 samples on bone char was determined relatively to adsorption capacity be $0.004 \mathrm{mg}$ arsenic ion/g bone char for As1 and as $0.02 \mathrm{mg}$ arsenic ion/g bone char for As5, at 90 minutes of time. This results are able to open an large application of bone char in removal arsenic ion contained waste water in industry.

Due to having a high adsorption capacity of bone char, further studies are needed to go on the experimental direction for other metal ions, especially heavy metal ions in next time. In addition, this work is only the bigining of adsorption. Many steps in adsorption processing such as kintics and thermodynamics will be investigate also in the next reseach.

\section{ACKNOWLEDGMENT}

The authors gratefully acknowledge a grant received from research fund of Industrial University of Ho Chi Minh City in support for this research.

\section{REFERENCES}

[1] D. Bomford, Kirby J., Leighton J., Roy A. Art in the Making: Impressionism. National Gallery Publications, London, 1990, tr. 112-119.

[2] Édouard Manet, 'Music in the Tuileries Gardens', ColourLe Asadi, Mosen (2006), Beet-Sugar Handbook. Hoboken: John Wiley \& Sons. p. 333. ISBN 9780471790983.

[3] Chou, ed. by Chung Chi (2000). Handbook of sugar refining: a manual for the design and operation of sugar refining facilities. New York, NY [u.a.]: Wiley. pp. 368-369. ISBN 9780471183570.

[4] Chou, Chung Chi biên tập (2000). Handbook of sugar refining: a manual for the design and operation of sugar refining facilities. New York, NY: Wiley. tr. 368-369. ISBN 9780471183570.

[5] Reynel-Avila HE, Mendoza-Castillo DI and Bonilla-Petriciolet A (2016). Relevance of anionic dye properties on water decolorization performance using bone char: Adsorption kinetics, isotherms and breakthrough curves. Journal of Molecular Liquids, 219: 425-434.

[6] Tovar Gómez, José Luis Alcántara Flores, Maria Ana Perez-Cruz, and Miguel Ángel Montes Morán (2016). Adsorotion of heavy metals in the presence of a magnetic field on adsorbents with diferent magnetic properties. Ind. Eng. Chem. Res., 1-34.

[7] CK. Rojas-Mayorga, DI. Mendoza-Castillo, A. Bonilla-Petriciolet, J. Silvestre-Albero (2016). Tailoring the adsorption behavior of bone char for heavy metal removal from aqueous solution. Adsorption Science \& Technology, 34(6): 368-387. 


\section{WASTEWATER TREATMENT CONTAINED ARSENIC ION}

[8] Mendoza-Castillo DI, Bonilla-Petriciolet A and Ja' uregui-Rinco'n J (2015). On the importance of surface chemistry and composition of bone char for the sorption of heavy metals from aqueous solution. Desalination and Water Treatment, 54: 1651-1662.

[9] Pan X, Wang J and Zhang D (2009). Sorption of cobalt to bone char: Kinetics, competitive sorption and mechanism. Desalination, 249: 609-614.

[10] L.E. Hernández-Hernández, A. Bonilla-Petriciolet, D.I. Mendoza-Castillo, H.E. Reynel-Ávila (2017). Antagonistic binary adsorption of heavy metals using stratified bone char columns, Journal of Molecular Liquids, 241: 334-346.

[11] Medellin-Castillo Nahum A., Leyva-Ramos Roberto, Ocampo-Perez Raul, Garcia de la Cruz Ramon F., Aragon-Piña Antonio, Martinez-Rosales Jose M., Guerrero-Coronado Rosa M., Fuentes-Rubio Laura (2007). "Adsorption of Fluoride from Water Solution on Bone Char". Industrial \& Engineering Chemistry Research, 46 (26): 9205-9212. doi:10.1021/ie070023n.

[12] Horowitz H. S., Maier F. J., Law F. E (1967). "Partial defluoridation of a community water supply and dental fluorosis", Public Health Reports, 82 (11): 965-72. doi:10.2307/4593174.

[13] Mjengera H., Mkongo G (2003). "Appropriate deflouridation technology for use in flourotic areas in Tanzania". Physics and Chemistry of the Earth, Parts A/B/C., 28 (20-27): 10971104. doi:10.1016/j.pce.2003.08.030.

[14] Ko Danny C.K., Porter John F., McKay Gordon (2000). "Optimised correlations for the fixed-bed adsorption of metal ions on bone char", Chemical Engineering Science, 55 (23): 5819-5829. doi:10.1016/S00092509(00)00416-4.

[15] Chen, Yun-Nen, Chai Li-Yuan, Shu Yu-De (2008). "Study of arsenic(V) adsorption on bone char from aqueous solution", Journal of Hazardous Materials, 160 (1): 168-172. doi:10.1016/j.jhazmat.2008.02.120.

[16] Deydier, Eric; Guilet, Richard; Sharrock, Patrick (2003). "Beneficial use of meat and bone meal combustion residue: "an efficient low cost material to remove lead from aqueous effluent"", Journal of Hazardous Materials, 101 (1): 55-64. doi:10.1016/S0304-3894(03)00137-7.

[17] Chen Yun-Nen, Chai Li-Yuan, Shu Yu-De (2008). "Study of arsenic(V) adsorption on bone char from aqueous solution", Journal of Hazardous Materials, 160 (1): 168-172. doi:10.1016/j.jhazmat.2008.02.120.

[18] "Water-Nanofilter". Gongalimodel.com. Deydier Eric, Guilet Richard, Sharrock Patrick (2003). "Beneficial use of meat and bone meal combustion residue: "an efficient low cost material to remove lead from aqueous effluent"", Journal of Hazardous Materials, 101 (1): 55-64. doi:10.1016/S0304-3894(03)00137-7.

[19] "Water-Nanofilter". gongalimodel.com.

[20] Alijani H., Beyki M.H., Shariatinia Z., Bayat M., Shemirani F (2014). A new approach for one step synthesis of magnetic carbon nanotubes/diatomite earth composite by chemical vapor deposition method: Application for removal of lead ions, Chem. Eng. J., 253, 456-463.

[21] Chen G., Qiao C., Wang Y., Yao J (2014). Synthesis of magnetic gelatin and its adsorption property for Cr(VI), Ind. Eng. Chem. Res., 53, 15576-15581.

[22] Tang W.W., Zeng G.M., Gong J.L., Liang J., Xu P., Zhang C., Huang B.B. (2014), Impact of humic/ fulvic acid on the removal of heavy metals from aqueous solutions using nanomaterials: A review. Science of the Total Environment, 468:1014-1027. DOI: 10.1016/j. scitotenv.2013.09.044

[23] Hernandez-Montoya V., Perez-Cruz M.A., Mendoza-Castillo D.I., Moreno-Virgen M.R., Bonilla-Petriciolet A (2013). Competitive adsorption of dyes and heavy metals on zeolitic structures. J. Environ. Manage. 116, 213-221.

[24] Grund Sabina C., Hanusch Kunibert, Wolf Hans Uwe, "Arsenic and Arsenic Compounds", Ullmann's Encyclopedia of Industrial Chemistry, Weinheim: Wiley-VCH, 15 October 2008. 
WASTEWATER TREATMENT CONTAINED ARSENIC ION

[25] Dibyendu, Sarkar; Datta, Rupali (2007). "Biogeochemistry of Arsenic in Contaminated Soils of Superfund Sites". EPA. United States Environmental Protection Agency. Retrieved 25 February 2018.

[26]. Carelton, James (2007). "Final Report: Biogeochemistry of Arsenic in Contaminated Soils of Superfund Sites". EPA. United States Environmental Protection Agency. Retrieved 25 February 2018. Sakurai, Teruaki Sakurai (2003). "Biomethylation of Arsenic is Essentially Detoxicating Event", Journal of Health Science, 49 (3): 171-178. doi:10.1248/jhs.49.171.

[27] Reimer K. J., Koch I., Cullen, W.R (2010). "Organoarsenicals. Distribution and transformation in the environment", Metal ions in life sciences, 7: 165-229. doi:10.1039/9781849730822-00165.

[28] Bentley Ronald, Chasteen T. G (2002). "Microbial Methylation of Metalloids: Arsenic, Antimony, and Bismuth", Microbiology and Molecular Biology, 66 (2): 250-271. doi:10.1128/MMBR.66.2.250- 271.

[29] Cullen William R., Reimer Kenneth J (1989). "Arsenic speciation in the environment", Chemical Reviews, 89 (4): 713-764. doi:10.1021/cr00094a002.

[30] "NIOSH Pocket Guide to Chemical Hazards \#0038". National Institute for Occupational Safety and Health (NIOSH).

[31] "NIOSH Pocket Guide to Chemical Hazards \#0039". National Institute for Occupational Safety and Health (NIOSH).

[32] Demirbas A (2008). Heavy metal sorption onto agro-based waste materials: a re-view. J. Hazard. Mater 157, $220 \mathrm{e} 229$

[33] Adąbrowski (2001). Adsorption — from theory to practice, Advances in Colloid and Interface Science, 93(13), 8: 135-224.

[34] Vo Thanh Cong, Tran Tan Nhat, Do Quy Diem, Nguyen Van Son (2019). The Study of Vietnamese Bone char Synthesis and its Applications in Removal Organic Color. Asian Journal of Applied Sciences. 07. 02. 23210893.

Ngày nhận bài: 27/02/2019

Ngày chấp nhận đăng: 16/05/2019 